\title{
IQTISHODUNA
}

Vol. 16 (2), 2020

P-ISSN: 1829-524X, E-ISSN: 2614-3437

\section{Studi Mediasi Kepuasan Pelanggan Pada Industri Retail: Peran Kualitas Layanan dan Implikasinya terhadap Loyalitas Pelanggan}

\author{
Muhammad Nur Safri Ramadhan', Nur Asnawi ${ }^{2 *}$ \\ UIN Maulana Malik Ibrahim Malang
}

*Corresponding Author:
E-mail: asnawi@manajemen.uin-malang.ac.id

\begin{abstract}
The purpose of this research is to determine the direct effect of retail service quality on customers' loyalty and satisfaction, the effect of customer satisfaction on their loyalty and how much customer satisfaction mediates retail service quality on customers' loyalty on Super Indo Bendungan Sutami customers, Malang. This research method uses comparative research with a quantitative approach. The sample used was 120 respondents with collected data by a questionnaire. The data analysis in this study used the Partial Least Square (PLS) method. The results of this research indicate that there is a direct effect of the retail service quality variable upon customers' loyalty and also on customer satisfaction which has a direct influence on customers of Super Indo Bendungan Sutami. Meanwhile, loyalty and can mediate the effect of retail service quality on customer loyalty.
\end{abstract}

Keywords: marketing mix, customer satisfaction, customer loyalty

\begin{abstract}
Abstrak: Tujuan dari penelitian ini adalah untuk mengetahui pengaruh langsung kualitas layanan ritel terhadap loyalitas dan kepuasan pelanggan, pengaruh kepuasan pelanggan terhadap loyalitas mereka dan seberapa besar kepuasan pelanggan memediasi kualitas layanan ritel terhadap loyalitas pelanggan pada pelanggan Super Indo Bendungan Sutami, Malang. Metode penelitian ini menggunakan penelitian komparatif dengan pendekatan kuantitatif. Sampel yang digunakan adalah 120 responden dengan data yang dikumpulkan dengan kuesioner. Analisis data dalam penelitian ini menggunakan metode Partial Least Square (PLS). Hasil penelitian ini menunjukkan bahwa ada pengaruh langsung dari variabel kualitas layanan ritel terhadap loyalitas pelanggan dan juga terhadap kepuasan pelanggan yang memiliki pengaruh langsung terhadap pelanggan Super Indo Bendungan Sutami. Sementara itu loyalitas dan mampu memediasi pengaruh kualitas layanan ritel terhadap loyalitas pelanggan.
\end{abstract}

Kata kunci: marketing mix, kepuasan konsumen, loyalitas konsumen 


\section{Cara mencitasi:}

Ramadhan, M.N.S dan Asnawi, N. (2020). Studi Mediasi Kepuasan Pelanggan Pada Industri Retail: Peran Kualitas Layanan dan Implikasinya terhadap Loyalitas Pelanggan. Iqtishoduna, 16 (2), 115-130.

\section{Pendahuluan}

Dalam era globalisasi dewasa ini, dunia bisnis semakin berkembang pesat yang menyebabkan pertumbuhan ataupun perlambatan bagi perekonomian suatu negara tidak terkecuali Indonesia. Salah satu sektor yang mengalami dampak adalah sektor ritel. Di zaman modern ini membuat kecerdasan konsumen dalam memilih barang atau jasa pun semakin tinggi. Hal ini menutut perusahaan ritel untuk selalu memperhatikan kebutuhan dan keinginan konsumen memberikan pelayanan yang lebih memanjakan dan memuaskan pelanggan dibandingkan pesaing. Kota Malang merupakan kota pendidikan yang memiliki banyak pendatang baru yang sangat mempengaruhi peningkatan tingkat konsumsi masyarakat. Hal ini juga mempengaruhi pergeseran pola budaya berbelanja masyarakat dari pola berbelanja yang tradisional menuju ke arah pola berbelanja yang lebih modern. Hal tersebut tentu berdampak besar pada bisnis ritel yang ada di Indonesia yang menyebabkan peritel harus menemukan strategi-strategi baru guna memenangkan persaingan. Salah satu strategi yang dapat digunakan adalah dengan memberikan pelayanan terbaik guna memenuhi kebutuhan dan keinginan konsumen dalam melakukan traksaksi.

Pada penelitian yang dilakukan oleh Hendra et al. (2017) menunjukkan bahwa kepuasan pelanggan merupakan variabel yang signifikan terhadap loyalitas pelanggan. Temuan ini di perkuat oleh penelitian yang dilakukan Claudia et al. (2017) yang hasilnya kepuasan pelanggan merupakan hal yang signifikan mempengaruhi loyalitas pelanggan. Terdapat berbagai cara untuk mencapai kepuasan pelanggan, dan salah satunya melalui meningkatkan kualitas pelayanan yang di berikan kepada konsumen. Kualitas layanan dapat di ukur dengan berbagai cara, salah satunya dengan menggunakan retail service quality yang dapat mengukur tingkat kepuasan konsumen. Ritel service quality sudah di uji di berbagai negara dan di anggap mampu untuk 
mengukur kualitas jasa layanan ritel. Penelitian sebelumnya hanya mengukur kepuasan terhadap loyalitas pelanggan dengan menggunakan pendekatan retail service quality. Sedangkan dalam penelitian ini mengukur apakah kepuasan pelanggan dapat memediasi terhadap loyalitas pelanggan.

Dalam memberikan kualiatas pelayanan, Super Indo Bendungan Sutami selalu memberikan pelayanan terbaik dan terus memberikan terobosanterobosan baru guna memberikan kepuasan dan kenyamanan dalam melakukan transaksi. Alasan yang mendasari Super Indo Bendungan Sutami menjadi objek utama dalam penelitian ini yaitu, meskipun banyak pesaing serupa Super Indo Bendungan Sutami tetap menjadi supermarket andalan masyarakat yang berada di daerah Kota Malang. Selain itu, pelanggan dari Super Indo Bendungan Sutami adalah kaum-kaum pendidikan atau sebagai generasi milenial yang bertempat tinggal sementara di daerah sekitaran Bendungan Sutami. Tujuan penelitian ini adalah menguji pengaruh langsung ritel service quality terhadap customer satisfaction pada Super Indo Bendungan Sutami, menguji pengaruh langsung ritel service quality terhadap customer loyalty pada Super Indo Bendungan Sutami, menguji pengaruh tidak langsung retail service quality terhadap customer loyalty melalui customer satisfaction pada ritel Super Indo Bendungan Sutami Kota Malang.

\section{Kajian Pustaka}

\section{Ritel Service Quality Scale}

Utami (2017) menunjukan bagaimana perkembangan pemikiran tentang konsep kualitas jasa, yang sebenarnya diawali oleh pemikiran Gronroos dengan menggunakan dua dimensi dalam menilai kualitas jasa layanan. Service Quality dalam ritel memiliki perbedaan yang signifikan dari lingkungan hidup produk atau jasa lainnya. Dengan alasan tersebut retail service quality muncul atas dasar model service quality mengenai dimensi pengukuran yang digunakan untuk mengukur kualitas pelayanan. Dabholkar, et al. dalam (Tjiptono, 2000) mengkritik bahwa model service quality tidak mampu menjelaskan secara akurat persepsi pelanggan terhadap kualitas jasa/layanan toko ritel (pasar swalayan, toserba, dan specialty store). Lebih lanjut, Dabholkar et al. (dalam Tjiptono, 2014) mengajukan struktur faktor hirarkis kualitas jasa ritel. Utami (2017) juga menyebutkan bahwa Dabholkar et al. menggunakan analisis faktor persetujuan (confirmatory factor analysis), menetapkan 28 atribut, dimana 17 atribut diadopsi dari service quality ditambahkan 11 unit baru. Skala pengukuran ini terdiri dari 5 dimensi, yaitu physical aspect, reliability, personal interaction, problem solving, dan policy.

IQTISHODUNA Vol. 16 (2), $2020 \mid 117$

http://ejournal.uin-malang.ac.id/index.php/ekonomi 


\section{Kualitas Layanan}

Menurut Tjiptono (2000) pada dasarnya kualitas jasa berupaya fokus untuk pemenuhan kebutuhan dan keinginan pelanggan serta ketepatan penyampaiannya untuk mengimbangi ekspetasi pelanggan. Sedangkan menurut Olson dan Wycoff (dalam Yamit, 2011) melakukan penelitian serta pengamatan terhadap jasa pelayanan dan mensimpulkan bahwa jasa pelayanan adalah sekelompok manfaat yang memiliki daya guna secara eksplisit maupun inplisit atas kemudahan untuk mendapatkan barang maupun jasa pelayanan. Selain itu, definisi dari kualitas jasa yaitu menurut Lupiyoadi (2014) kualitas jasa adalah sejauh mana jasa memenuhi berbagai spesifikasinya. Dari beberapa uraian di atas dapat diartikan bahwa kualitas layanan adalah tingkat keunggulan yang diharapkan oleh konsumen untuk dapat memenuhi keinginan serta kepuasan pelanggan dalam memenuhi kebutuhannya. Kualitas layanan dapat diukur dari kepuasan pelanggan terhadap pelayanan yang diberikan oleh perusahaan.

\section{Kepuasan Pelanggan}

Kotler (2000) menyatakan bahwa kepuasan merupakan yang muncul setelah membandingkan antara hasil kinerja produk yang dirasakan dengan hasil kinerja yang diharapkan pelanggan kemudian menghasilkan perasaan senang atau kecewa seseorang. Apabila kinerja berada di bawah harapan, pelanggan tidak puas. Sebaliknya, jika kinerja sesuai dengan harapan pelanggan maka pelanggan akan merasa puas. Lebih lanjut lagi apabila kinerja melebihi harapan, pelanggan sangat puas atau senang. Dapat diartikan secara umum bahwa pengertian kepuasan atau ketidakpuasan pelanggan dapat dilihat dari kesesuaian antara ekspetasi pelanggan dengan persepsi pelayanan yang dirasakan secara langsung. Menurut Zethaml et al. (2009) menemukan tiga indikator customer satisfaction yang dapat ditentukan, yakni fulfillment, pleasure, dan Ambivalence.

\section{Loyalitas Pelanggan}

Tujuan utama suatu bisnis adalah untuk memberikan pelayanan yang baik guna menciptakan kepuasan pelanggan. Menurut Tjiptono (2000), terdapat beberapa manfaat dari terciptanya kepuasan pelanggan, salah satunya adalah hubungan antara pelanggan dengan perusahaan menjadi harmonis sehingga dapat memberikanlandasan yang baik untuk melakukan pembelian ulang atau bahkan dapat menciptakan kesetiaan terhadap merek untuk dapat membuat sebuah rekomendasi dari mulut ke mulut (word of mouth) yang dapat memberikan keuntungan bagi perusahaan. Sedangkan menurut Griffin (2002) konsumen yang memiliki kategori loyal adalah

118 | IQTISHODUNA Vol. 16 (2), 2020

http://ejournal.uin-malang.ac.id/index.php/ekonomi 
konsumen yang melakukan pembelian ulang secara teratur, pembelian di seluruh lini produk dan layanan, merujuk orang lain dan dapat memberikan kekebalan terhadap tawaran-tawaran dari pesaing. Menurut Oliver dalam Kotler (2000) mengemukakakn beberapa indikator dari konsumen yang memiliki sikap loyal yaitu, Repeat Purchase, Retention, dan Referalls.

\section{Hipotesis Penelitian}

H1. ritel service quality berpengaruh langsung terhadap customer satisfaction pada Super Indo Bendungan Sutami

H2. ritel service quality berpengaruh langsung terhadap customer loyalty pada Super Indo Bendungan Sutami

H3. retail service quality berpengaruh tidak langsung terhadap customer loyalty melalui customer satisfaction pada ritel Super Indo Bendungan Sutami Kota Malang.

\section{Metodologi Penelitian}

Jenis penelitian ini merupakan penelitian komparatif dengan pendekatan penelitian kuantitatif. Penelitian Penelitian komparatif atau casual comparative research adalah jenis penelitian deskriptif yang ingin mencari dengan cara menganalisis faktor-faktor penyebab terjadinya atau munculnya suatu fenomena tertentu untuk mendapat jawaban secara mendasar terkait dengan adanya sebab akibat. Metode penelitian komparatif adalah bersifat ex post facto, artinya data dikumpulkan setelah semua kejadian yang dikumpulkan telah selesai berlangsung (Asnawi dan Masyhuri, 2011). Penelitian kausal meneliti terkait hubungan sebab-akibat antara dua variabel atau lebih. Lebih lanjut penelitian tersebut juga memberikan penjelasan tentang pengaruh perubahan variasi nilai dalam sebuah variabel terhadap suatu perubahan variasi pada nilai variabel lain. Dalam penelitian kausal, variabel independen sebagai variabel sebab dan variabel dependen sebgai variabel akibat (Silalahi, 2009).

Metode pengumpulan data dalam penelitian ini menggunakan beberapa metode yaitu, instrument kuesioner, dokumentasi, dan observasi. Populasi pada Super Indo Bendungan Sutami dapat dikategorikan sebagai populasi yang tak terbatas, maka sampel dalam penelitian ini berjumlah 120 responden agar data yang di ambil dapat lebih akurat serta dapat menjadi pembeda dengan penelitian sebelumnya. Teknik pengumpulan sampel yang digunakan dalam penelitian ini adalah dengan metode purposive sampling atau yang dikenal dengan sampel pertimbangan yang digunakan peneliti jika peneliti mempunyai pertimbangan-pertimbangan tertentu dalam mengambil sampel atau penentu sampel untuk tujuan tertentu (Asnawi dan Masyhuri,

IQTISHODUNA Vol. 16 (2), $2020 \mid 119$ http://ejournal.uin-malang.ac.id/index.php/ekonomi 
2011). Hal tersebut dikarenakan sampel memiliki kriteria sebagai berikut:

1. Konsumen yang pernah melakukan transaksi di Super Indo Bendungan Sutami Kota Malang.

2. Berusia minimal 17 tahun.

Dalam melakukan penelitian ini peneliti menggunakan analisis jalur (path analysis), T-test dan statistik deskriptif. Dalam penelitian ini, model yang digunakan lebih dari satu dependen variabel, maka penyelesaian model menggunakan teknik SEM atau Structural Equation Modeling. Proses pemodelan SEM terdiri atas dua tahapan dasar, yakni validasi model pengukuran dan pegujian model structural. Pengujian statistik pada model path analysis dilakukan dengan menggunakan metode partial least square atau PLS dengan proses perhitungan mengunakan software Smart PLS 3.0. Partial Least Square (PLS) merupakan software analisis statistik yang kegunaanya mirip dengan SEM di dalam analisis covariance. Abdillah dan Hartono (2015) mengungkapkan bahwa salah satu kelebihan PLS-SEM yakni mampu menangani model yang kompleks dengan menggunakan multiple variabel eksogen dan endogen dengan beberapa indikator, dapat digunakan pada sampel atau responden yang memiliki jumlah sedikit, dan data distribusi yang lebih condong. Jawaban pada penelitian ini dijelaskan dalam lima skala pernyataan dengan menggunakan skala likert. Menurut Chin dalam (Jogiyanto dan Willy, 2009) uji validitas diskriminan atau Discriminant validy dapat dinilai berdasarkan cross loading pengukuran dengan konstruknya. Berikut tabulasi parameter uji validitas dalam PLS disajikan pada Tabel 1.

Tabel 1. Parameter Uji Validitas dalam Model Pengukuran PLS

\begin{tabular}{ccc}
\hline Uji Validitas & Parameter & Rule of Thumbs \\
\hline Konvergen & Faktor loading & Lebih dari 0.7 \\
& Average Variance & Lebih dari 0.5 \\
& Extarcted (AVE) & \\
& Communality & Lebih dari 0.5 \\
Diskriminan & Akar AVE dan korelasi & Akar AVE $>$ Korelasi \\
& variabel laten & variabel laten \\
& Cross loading & Lebih dari 0.7 \\
\hline
\end{tabular}

Hair et al. dalam Jogianto dan Abdillah (2015) rule of thumb nilai alpha atau composite reliability harus lebih besar dari 0,7 tetapi apabila nilai 
menunjukan angka 0,6 rule of thumb nilai alpha atau composite reliability masih dapat di terima. Hartono dan Abdillah (2015) mengatakan bahwa konstruk yang valid adalah konstruk yang reliabel, sebaliknya konstruk yang reliabel belum tentu valid, karena sejatinya uji konsistensi internal tidak mutlak untuk dilakukan jika validitas konstruk telah terpenuhi.

\section{Hasil Penelitian}

\section{Karakteristik Responden}

Berdasarkan Tabel 2 dapat diketahui dari 120 responden, mayoritas responden adalah perempuan terdiri dari 91 orang atau75,8\% lebih banyak dibandingkan responden laki-laki terdiri dari 29 orang atau $24,2 \%$.

Tabel 2 Distribusi Frekuensi Berdasarkan Jenis Kelamin

\begin{tabular}{|c|c|c|c|c|c|}
\hline & & Frequency & Percent & $\begin{array}{c}\text { Valid } \\
\text { Percent }\end{array}$ & $\begin{array}{c}\text { Cumulative } \\
\text { Percent }\end{array}$ \\
\hline \multirow[t]{3}{*}{ Valid } & Laki & 29 & 24,2 & 24,2 & 24,2 \\
\hline & Perempuan & 91 & 75,8 & 75,8 & 100,0 \\
\hline & & 120 & 100,0 & 100,0 & \\
\hline
\end{tabular}

Tabel 3 Distribusi Frekuensi Berdasarkan Usia

\begin{tabular}{|c|c|c|c|c|c|}
\hline & & Frequency & Percent & $\begin{array}{c}\text { Valid } \\
\text { Percent }\end{array}$ & $\begin{array}{c}\text { Cumulative } \\
\text { Percent }\end{array}$ \\
\hline \multirow[t]{3}{*}{ Valid } & 17-27 tahun & 119 & 99,2 & 99,2 & 99,2 \\
\hline & $\begin{array}{l}>27-37 \\
\text { tahun }\end{array}$ & 1 & 0,8 & 0,8 & 100,0 \\
\hline & & 120 & 100,0 & 100,0 & \\
\hline
\end{tabular}

Berdasarkan Tabel 3 dapat diketahui dari 120 responden, mayoritas responden sebanyak 119 orang atau99,2\% berusia antara 17 sampai dengan 27 tahun dan hanya 1 orang atau 0,8\% yang berusia antara 27 sampai dengan 37 tahun. 
Tabel 4 Distribusi Frekuensi Berdasarkan Pekerjaan

\begin{tabular}{lcrrrr}
\hline & Frequency & Percent & $\begin{array}{c}\text { Valid } \\
\text { Percent }\end{array}$ & $\begin{array}{c}\text { Cumulative } \\
\text { Percent }\end{array}$ \\
\hline Valid & Barista - Weiters & 1 &, 8 &, 8 &, 8 \\
& Karyawan Swasta & 3 & 2,5 & 2,5 & 3,3 \\
& Pelajar/Mahasiswa & 116 & 96,7 & 96,7 & 100,0 \\
\hline Total & & 120 & 100,0 & 100,0 & \\
\hline
\end{tabular}

Berdasarkan Tabel 4 dapat diketahui dari 120 responden, mayoritas respondenadalah yang bemiliki pekerjaan sebagai pelajar/mhasiswa yaitu sebanyak116 orang atau96,7\%, 3 orang atau 2,5\% bekerja sebagai karyawan swasta, dan yang paling sedikit adalah yang bekerja sebagai barista - weiters yaitu hanya 1 orang atau $0,8 \%$.

\section{Evaluasi Model}

Evaluasi model pengukuran (outer model) meliputi pengecekan individual hasil dari convergent validity (dilihat dari nilai outer loadings), average variance extracted, cronbach alpha, dan composite reliability.

\section{Convergent Validity}

Korelasi antara item score dengan construct score dari model pengukuran dengan indikator refleksif dinilai dapat mengukur tingkat convergent validity berdasarkan yang dihitung dengan PLS. Pada pengujian ini terlihat bahwa nilai loading factor dari indikator telah memenuhi kriteria uji validitas, dikarenakan loading factor pada masing-masing indikator (item pertanyaan) lebih besar dari 0,5. Chin dalam Ghozali (2008) menyatakan penelitian tahap awal dari pengembangan skala pengukuran nilai loading 0,5 sampai 0,6 dianggap cukup.

Berdasarkan hasil pengujian diketahui bahwa keseluruhan loading factor CFA first order menunjukkan bahwa model sudah memenuhi syarat convergent validity karena nilai loading factor sudah lebih dari 0,5 dan nilai $t$ statistic lebih dari 1,96. Artinya seluruh indikator valid sebagai alat ukur untuk variabelnya masing-masing pada variabel retail service quality scale, customer satisfaction, dan customer loyalty.

\section{Average Variance Extracted (AVE)}

Model memiliki discriminant validity yang cukup dilihat dari nilai AVE, dikatakan valid jika nilai AVE lebih besar dari 0,5 (Yamin \& Kurniawan, 2011). Hasil pengujian disriminant validity disajikan pada Tabel 5.

122 | IQTISHODUNA Vol. 16 (2), 2020

http://ejournal.uin-malang.ac.id/index.php/ekonomi 
Tabel 5. Average Variance Extracted (AVE)

\begin{tabular}{cc}
\hline Variabel & (AVE) \\
\hline Retail Service Quality & 0,603 \\
Customer Satisfaction & 0,670 \\
Customer Loyalty & 0,754 \\
\hline
\end{tabular}

Berdasarkan Tabel 5 terlihat bahwa seluruh nilai nilai AVE $>0,5$, hal ini menunjukkan bahwa semua variabel laten dalam model yang diestimasi memenuhi kriteria discriminant validity (valid).

\section{Composite Realibility}

Jika nilai output composite reliability lebih besar dari 0,7 maka konstruk dinyatakan reliabel (Yamin, 2011). Berikut adalah hasil output dari Composite Reliability dan Cronbach's Alpha disajikan pada Tabel 6.

Tabel 6. Nilai Composite Reliability dan Cronbach's Alpha

\begin{tabular}{ccc}
\hline Variabel & Cronbach's Alpha & $\begin{array}{c}\text { Composite } \\
\text { Reliability }\end{array}$ \\
\hline Retail Service Quality & 0,963 & 0,966 \\
Customer Satisfaction & 0,877 & 0,910 \\
Customer Loyalty & 0,919 & 0,939 \\
\hline
\end{tabular}

Hasil pengujian reliabilitas konstruk sebagaimana disajikan pada tabel 6 menunjukkan nilai Composite Reliability dan Cronbachs Alpha dari semua variabel laten $>0,70$. Sehingga semua dimensi dalam mengukur variabel laten dalam model yang diestimasi dinyatakan reliabel. Dengan demikian pengujian model struktural (inner model) dapat dilanjutkan.

\section{Analisa Model Struktural}

Pengujian inner model atau model struktural dilakukan untuk melihat hubungan antara variabel, nilai signifikansi dan Rsquare dari model penelitian. Pengujian hipotesis dilakukan dengan metode resampling bootstraping. Statistik uji yang digunakan adalah uji statistik uji t. Berikut ini hasil evaluasi model struktural disajikan pada Tabel 7. 
Tabel 7. Evaluasi Model Struktural

\begin{tabular}{ccccc}
\hline Variabel & R Square & $\begin{array}{c}\text { R Square } \\
\text { Adjusted }\end{array}$ & Q Square & GoF \\
\hline $\begin{array}{c}\text { Customer } \\
\text { Satisfaction } \\
\text { Customer } \\
\text { Loyalty }\end{array}$ & 0,597 & 0,594 & 0,815 & 0,620 \\
\hline
\end{tabular}

Hasil pengujian yang ditampilkan pada Tabel 7 menunjukkan nilai $\mathrm{R}^{2}$ customer satisfaction sebesar 0,597 $>0,5$ tergolong moderat, sementara nilai $\mathrm{R}^{2}$ customer loyalty sebesar 0,542 $>0,5$ tergolong moderat, dan $\mathrm{R}^{2}$ Adjusted masing-masing sebesar 0,594 $>0,5$ tergolong moderat, 0,534 $>0,50$ tergolong moderat. Sementara nilai predictive relevance $\left(Q^{2}\right)$ sebesar $0,815>$ 0,35 tergolong kategori kuat. Dengan demikian, secara keseluruhan, nilai Goodness of fit tergolong besar $(0,620>0,35)$. Nilai $R^{2}$ adjusted, predictive relevance $\left(Q^{2}\right)$ dan Goodness of fit menunjukkan bahwa model penelitian robust. Sehingga dapat disimpulkan bahwa model penelitian didukung oleh kondisi empiris atau model fit. Dengan demikian, karena model penelitian valid dan reliabel serta model fit maka pengujian hipotesis dapat dilanjutkan.

\section{Pengujian Hipotesis}

Sebelum dilakukan pengujian hipotesis, maka dapat dibuat persamaan model struktural berdasarkan hasil pengujian statistik yang disajikan pada Gambar 1. Hasil pengujian model memperlihatkan bahwa variabel retail service quality berpengaruh positif terhadap customer satisfaction. Pengaruh positif ini dapat dilihat dari nilai koefisien jalur (path coeffiicient) pada variabel yang menunjukkan nilai positif yaitu sebesar 0,773 (Retail Service Quality). Hasil pengujian model memperlihatkan bahwa variabel retail service quality, dan customer satisfaction berpengaruh positif terhadap customer loyalty. Pengaruh positif ini dapat dilihat dari nilai koefisien jalur (path coeffiicient) masing-masing variabel yang menunjukkan nilai positif yaitu sebesar 0,298 (Retail Service Quality), dan 0,481 (Customer Satisfaction). 


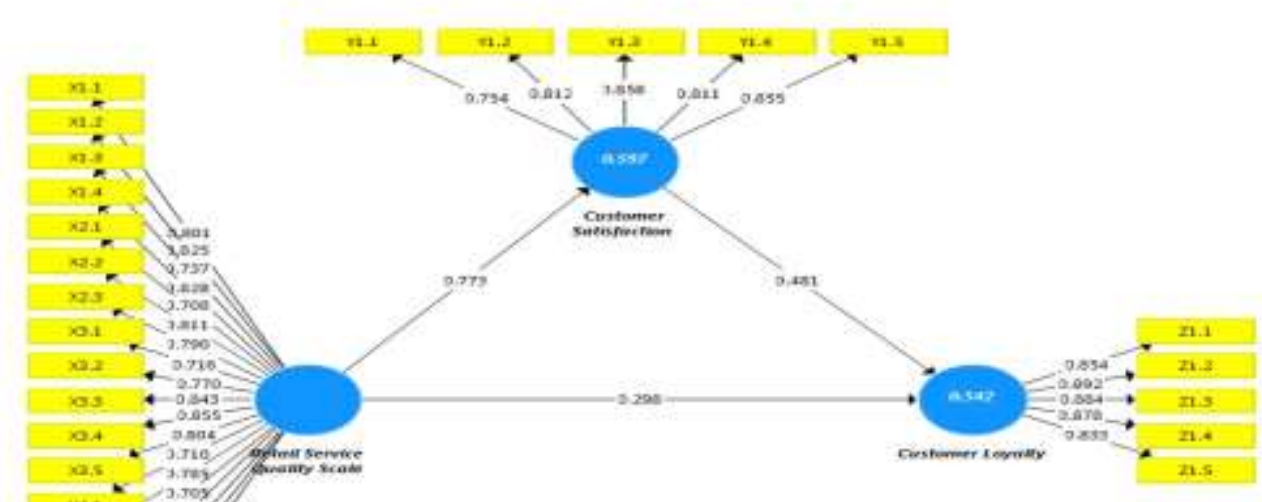

Gambar 1. Hasil Pengujian Hipotesis

Tabel 8. Hasil Pengujian Hipotesis

\begin{tabular}{ccccc}
\hline & $\begin{array}{c}\text { Original } \\
\text { Sample }\end{array}$ & $\begin{array}{c}\text { T } \\
\text { Statistics }\end{array}$ & P Values & $\begin{array}{c}\text { Keterang } \\
\text { an }\end{array}$ \\
\hline $\begin{array}{c}\text { Retail Service Quality -> } \\
\text { Customer Satisfaction }\end{array}$ & 0,773 & 14,538 & 0,000 & Signifikan \\
$\begin{array}{c}\text { Retail Service Quality -> } \\
\text { Customer Loyalty }\end{array}$ & 0,298 & 2,362 & 0,019 & Signifikan \\
$\begin{array}{c}\text { Retail Service Quality -> } \\
\text { Customer Satisfaction -> } \\
\text { Customer Loyalty }\end{array}$ & 0,372 & 3,707 & 0,000 & Signifikan \\
\hline
\end{tabular}

Pengolahan data yang dilakukan pada penelitian ini menggunakan aplikasi SEM-PLS SmartPLS versi 3. Pengolagan data dilakukan untuk mengetahui bentuk model, loading factor, signifikansi pada masing-masing variabel laten maka, data yang sudah terisi oleh responden dijadikan satu dalam sebuah tabulasi data tipe CSV (Comma Separated Values). Pengolahan data menggunakan SEM-PLS ini dilakukan running data sehingga terpenuhi validitas dan reliabilitasnya.

Hasil pengujian hipotesis, menunjukan bahwa ritel service quality (X) berpengaruh secara signifikan terhadap customer satisfaction (Y). Hal tersebut dapat di lihat dari hasil pengujian yang menunjukkan nilai path 
coefficient sebesar 0,773 signifikan pada t-statistic 14,538 > t-tabel 1,96 dan pada P-value 0,000 < tingkat signifikansi 0,05. Dengan demikian Hipotesis yang menyatakan bahwa retail service quality berpengaruh langsung terhadap customer satisfaction dapat diterima, atau dengan kata lain retail service quality berpengaruh signifikan terhadap customer satisfaction.

Hasil pengujian hipotesis, menunjukan bahwa ritel service quality $(\mathrm{X})$ berpengaruh secara signifikan terhadap customer loyalty (Z). Hal tersebut dapat di lihat dari hasil pengujian yang menunjukkan nilai path coefficient sebesar 0,298 signifikan pada t-statistic 2,362 > t-tabel 1,96 dan pada P-value 0,019 < tingkat signifikansi 0,05. Dengan demikian Hipotesis yang menyatakan bahwa retail service quality berpengaruh langsung terhadap customer loyalty dapat diterima, atau dengan kata lain terdapat pengaruh yang signifikan dari retail service quality terhadap customer loyalty.

Hasil pengujian hipotesis, diperoleh hasil yakni nilai path coefficient sebesar 0,372 signifikan pada t-statistic 3,707 > t-tabel 1,96 dan pada P-value $0,000<$ tingkat signifikansi 0,05. Dengan demikian Hipotesis yang menyatakan bahwa terdapat pengaruh tidak langsung antara retail service quality terhadap customer loyalty yang dimediasi oleh customer satisfaction dapat diterima, dengan kata lain bahwa customer satisfaction mampu mediasi pengaruh retail service quality terhadap customer loyalty.

\section{Pembahasan}

\section{Pengaruh Retail Service Quality Terhadap Customer Satisfaction}

Berdasarkan model analisis jalur inner model, menunjukan bahwa ritel service quality $(\mathrm{X})$ berpengaruh secara signifikan terhadap customer satisfaction (Y). Hal tersebut dapat di lihat dari hasil pengujian yang menunjukkan nilai path coefficient sebesar 0,773 signifikan pada t-statistic 14,538 > t-tabel 1,96 dan pada P-value 0,000 < tingkat signifikansi 0,05. Hal ini menandakan, jika semakin baik kualitas layanan yang diberikan atau service quality maka akan mengakibatkan kepuasan pelanggan atau customer satisfaction. Demikian pula sebaliknya, jika semakin buruk layanan yang diberikan, maka pelanggan akan merasa tidak puas. Hasil penelitian di lapangan mendukung penelitian yang dilakukan oleh Tammubua (2017) yang menyebutkan bawah ritel service quality scale mempunyai pengaruh signifikan terhadap variabel customer satisfaction. Selain itu, Claudia et al. (2017) juga mendukung hasil penelitian dengan menyebutkan bahwa indikator yang ada pada ritel service quality scale berpengaruh terhadap 
customer satisfaction.

Retail service quality scale merupakan suatu hal yang penting bagi perusahaan jasa ritel, karena jasa bersifat tidak berwujud, tidak dapat dipisahkan, keanekaragaman, dan tidak tahan lama. Maka dari itu kepuasan akan sulit untuk di ukur menyeluruh secara valid, untuk itu Super Indo Bendungan Sutami harus terus memberikan pelayanan terbaik dan selalu melakukan evaluasi terhadap kekurangan yang dimiliki serta terus berinovasi dalam memberikan layanan guna bersaing dengan competitor agar dapat memberikan kepuasan terhadap konsumen. Dalam islam, penjual juga selalu di tuntut untuk memberikan pelayanan yang terbaik dalam setiap transaksi penjualannya, baik itu menyangkut kuantitas ataupun kualitas barang. Hal tersebut bersangkutan terhadap kejujuran dan larangan seseorang dalam melakukab transaksi untuk berbuat dholim terhadap hakhak orang lain atau pembeli, hal tersebut terkandung dalam surah AsySyu'ara ayat 181-183.

\section{Pengaruh Retail Service Quality Terhadap Customer Loyalty}

Berdasarkan model analisis jalur inner model, menunjukan bahwa ritel service quality $(\mathrm{X})$ berpengaruh secara signifikan terhadap customer loyalty (Z). Hal tersebut dapat di lihat dari hasil pengujian yang menunjukkan nilai path coefficient sebesar 0,298 signifikan pada t-statistic 2,362 > t-tabel 1,96 dan pada P-value 0,019 < tingkat signifikansi 0,05. Hasil tersebut menandakan apabila perusahaan memberikan pelayanan dengan baik akan menciptakan kesetiaan konsumen atau customer loyalty kepada perusahaan. Demikian sebaliknya, apabila layanan yang diberikan kepada konsumen buruk akan mengakibatkan kekecewaan terhadap konsumen yang berakibat tidak setianya konsumen terhadap layanan yang diberikan oleh perusahaan. Hasil penelitian ini mendukung penelitian yang telah dilakukan sebelumnya oleh Sivapalan dan Jebarajakirthy (2017) yang dilakukan di India, mengatakan bahwa variabel retail service quality berpengaruh positif atau signifikan terhadap customer loyalty terutama pada dimensi aspek fisik, interaksi personal, serta kebijakan. Penelitian lain yang dilakukan di Indonesia dilakukan oleh Ayuningtyas dan Saraswati (2019) yang mengatakan bahwa terdapat pengaruh langsung antara ritel service quality terhadap customer loyalty.

Customer loyalty merupakan suatu hal yang sangat penting, sebab dengan kesetiaan pelanggan terhadap perusahaan akan mengakibatkan pelanggan enggan untuk beralih pada perusahaan lain. Berdasarkan ritel service quality yang diciptakan Super Indo Bendungan sutami, perusahaan telah memberikan layanan yang baik terhadap pelanggan dan selalu 
memprioritaskan pelanggan dengan baik, sehingga akan menguntungkan kedua belah pihak dan menimbulkan customer loyalty dengan kesediaan pelanggan melakukan pembelian ulang, ketahanan dalam pengaruh negatif tentang perusahaan, dan memberikan referensi terhadap pihak lain.

\section{Pengaruh Retail Service Qualty Terhadap Customer Loyalty Melalui Customer Satisfaction}

Berdasarkan hasil pengujian yang telah dilakukan, diperoleh hasil yakni nilai path coefficient sebesar 0,372 signifikan pada t-statistic 3,707 > t-tabel 1,96 dan pada P-value $0,000<$ tingkat signifikansi 0,05 . Dengan demikian Hipotesis yang menyatakan bahwa terdapat pengaruh tidak langsung antara retail service quality terhadap customer loyalty yang dimediasi oleh customer satisfaction dapat diterima, dengan kata lain bahwa customer satisfaction mampu mediasi pengaruh retail service quality terhadap customer loyalty. Kepuasan pelanggan merupakan cara yang paling efektif untuk mengevaluasi dan memberikan inovasi terhadap langkah strategis yang dapat dilakukan oleh Super Indo Bendungan Sutami dalam mempertahankan pelanggannya. Jika kualitas layanan yang diberikan oleh Super Indo Bendungan Sutami di anggap memuaskan oleh konsumen maka pelanggan juga akan terus setia berbelanja pada perusahaan tersebut. Sehingga Super Indo harus berkomitmen untuk memberikan kualitas layanan guna mempertahankan kepuasan pelanggan dalam melakukan transaksi agar kedua belah pihak dapat menikmati feedback yang positif. Islam mengajarkan umatnya agar senantiasa melakukan segala aktivitasnya termasuk berkerja secara profesional dan sebaik mungkin.

\section{Kesimpulan}

Terdapat pengaruh langsung dan signifikan retail service quality terhadap customer satisfaction pada Super Indo Bendungan Sutami. Artinya, kualitas layanan yang diberikan oleh Super Indo Bendungan Sutami telah dilakukan dengan baik yang dapat menciptakan kepuasan pelanggan.

Terdapat pengaruh langsung dan signifikan retail service quality terhadap customer loyalty pada Super Indo Bendungan Sutami. Hasil tersebut menandakan bahwa konsumen Super Indo Bendungan Sutami mendapatkan pelayanan yang baik, oleh sebab itu konsumen dapat dikatakan loyal terhadap perusahaan yang akan membawa feedback positif untuk kedepannya.

Terdapat pengaruh langsung dan signifikan customer satisfaction terhadap customer loyalty pada Super Indo Bendungan Sutami. Artinya, bila 
pelanggan puas dengan maka akan menciptakan kestiaan pelanggan terhadap perusahaan. Begitu pula Super Indo Bendungan Sutami yang telah memberikan layanan yang maksimal kepada konsumen yang membuat perasaan puas atau senang yang mengakibatkan terciptanya kesetiaan pelanggan dalam melakukan transaksi dengan perusahaan.

Terdapat pengaruh yang signifikan retail service quality terhadap customer loyalty melalui customer satisfaction sebagai variabel perantara pada Super Indo Bendungan Sutami. Artinya, apabila pelanggan sudah merasa puas dengan kualitas layanan yang diberikan maka dapat memberikan kesan positif berupa loyalitas pelanggan yang berakibat pada pembelian ulang, ketahanan dalam pengaruh negatif pihak lain, dan merekomendasikan perusahaan kepada orang lain.

Keterbatasan dari penelitian ini adalah perlunya dilakukan pembahasan secara lebih mendalam serta secara keberlanjutan guna mendapatkan bukti yang lebih kuat mengenai arah dari hubungan setiap variabel dalam penelitian ini. Sehingga, peneliti selanjutnya diharapkan dapat mengurangi bias kesamaan dalam metode penelitian.

Adapun saran yang dapat dikemukakan antara lain: berdasarkan hasil dari kualitas layanan yang di ukur dengan ritel service quality perusahaan harus berkomitmen untuk selalu menjaga performa pelayanan untuk memberikan kepuasan serta loyalitas pelanggan; perusahaan harus lebih sering untuk menerima kritik dan saran serta melakukan perbaikan terhadap permasalahan yang bersangkutan. Untuk peneliti selanjutnya dapat melakukan pengujian dengan menambahkan variabel-variabel independen selain ritel service quality seperti faktor emosional, promosi, harga, produk dan lain sebagainya yang mampu memperkuat temuan kepuasan pelanggan dan loyalitas pelanggan.

\section{Daftar Pustaka}

Al-Qur'an al-Karim dan terjemahan cetakan Departemen Agama RI.

Abdillah, W., \& Hartono. (2015). Partial least square (PLS). Yogyakarta: Andi.

Asnawi \& Masyhuri. (2011). Metodologi Riset Manajemen Pemasaran. Malang: UIN Maliki Press.

Ayuningtias, K. S., \& Saraswati, T. G. (2019). Retail Service Quality and Customer Loyalty: A Case of IKEA Alam Sutera Retail Service. Jurnal Sekretaris Dan Administrasi Bisnis, III(1), 58-68.

Claudia, S., \& Japarianto, E. (2017). Analisis Retail Service Quality Terhadap Customer Loyalty Dengan Customer Satisfaction Sebagai Variabel Intervening Pada Supermarket Super Indo Merr Surabaya. Jurnal 
Strategi Pemasaran, 14(9), 1-8.

Ghozali, I. (2008). Structural equation modeling metode alterna-tive dengan partial least square. Semarang: Badan Penerbit Universitas Diponegoro.

Griffin, J. (2002). Customer Loyalty, How to Learn it How to Keep it. New York: Jossey-Bass

Hendra, T., Djawahir, A. H., \& Djazuli, A. (2017). Pengaruh Nilai, Kualitas Pelayanan, Pengalaman Pelanggan terhadap Kepuasan dan Loyalitas Pelanggan ( Studi Kasus Pada Giant Supermarket Sawojajar, Kota Malang ). Jurnal Bisnis Dan Manajemen, 4(2), 129-141.

Jogiyanto dan Abdillah, W. (2009). Konsep \& Aplikasi PLS (Partial least Square) Untuk penelitian Empiris. Eds. Pertama. Yogyakarta: BPFE Yogyakarta.

_. (2015). Partial Least Square (PLS) Alternatif Structural Equation Modeling (SEM) dalam Penelitian Bisnis. Ed.1. Yogyakarta: ANDI.

Kotler, P. (2000). Manajemen Pemasaran (Terjemahan), Edisi Milenium, Prehallindo, Jakarta.

Lupiyoadi, R. (2014). Manajemen Pemasaran Jasa. Edisi 3. Jakarta: Salemba Empat.

Sivapalan, A., \& Jebarajakirthy, C. (2017). An application of retailing service quality practices influencing customer loyalty toward retailers. Marketing Intelligence and Planning, 35(7), 842-857. https://doi.org/10.1108/MIP-09-2016-0178

Silalahi, U. (2009). Metode Penelitian Sosial. Bandung; PT. Refika Aditama.

Tjiptono, F. (2000). Manajemen Jasa: Edisi Kedua. Yogyakarta: Andy offset

F. (2014). Pemasaran Jasa: Prinsip, Penerapan, dan Penelitian. Yogyakarta: Andi.

Tammubua, M. H. (2017). Analisa Pengaruh Self Image Congruity, Retail Service Quality, Dan Customer Perceived Service Quality Terhadap Customer Loyalty Yang Dimediasi Customer Satisfaction Urban Surf / Distro Di Jayapura. Jurnal Organisasi Dan Manajemen, 13(2), 166-179.

Utami, C.W. (2017). Manajemen Ritel: Strategi dan Implementasi Operasional Bisnis Ritel Modern di Indonesia Edisi 3. Jakarta: Salemba Empat.

Yamin, S. dan Kurniawan, H. (2011). Generasi Baru Mengolah Data Penelitian dengan Partial Least Square Path Modeling: Aplikasi dengan Software XLSTAT, SmartPLS, dan Visual PLS. Jakarta: Salemba Infotek.

Yamit, Z. (2011). Manajemen Kualitas Produk dan Jasa. Yogyakarta: Ekonesia.

Zethaml, V., Bitner, M., \& Bitner, M. J. (2009). Service Marketing, Intergrating Customer Focus Across the Firm 5th Edition(5th ed.). McGraw Hill.

130 | IQTISHODUNA Vol. 16 (2), 2020

http://ejournal.uin-malang.ac.id/index.php/ekonomi 